Check for updates

Cite this: RSC Adv., 2021, 11, 1960

Received 9th December 2020

Accepted 18th December 2020

DOI: 10.1039/dOra10386a

rsc.li/rsc-advances

\title{
Oligo(amylene) from the reaction of fusel oil with zinc dihalide $\uparrow$
}

\author{
Matthew C. Davis, (DD *a Laszlo Prokai ${ }^{\text {(D) }}{ }^{\mathrm{b}}$ and Josanne Dee Woodroffe ${ }^{a}$ \\ Heating mixtures of fusel oil and zinc chloride or zinc bromide to $180^{\circ} \mathrm{C}$ gave water, difusel ethers and the \\ hydrocarbon oligo(amylene) as the major coproducts. Separation by chromatography gave oligo(amylene) \\ in $25 \%$ yield from fusel oil. The triamylene fraction of the oligo(amylene) had a net heating value of $43.9 \mathrm{~kJ}$ \\ $\mathrm{g}^{-1}$ which was $3 \%$ greater than specifications for gasoline, diesel \#2 and jet A-1. The cetane number of the \\ triamylene was 31.9 so it may not be useful for diesel engines. The triamylene had a flashpoint of $38^{\circ} \mathrm{C}$, \\ viscosity $\left(-20^{\circ} \mathrm{C}\right)$ of $7.85 \mathrm{~mm}^{2} \mathrm{~s}^{-1}$, density $\left(15^{\circ} \mathrm{C}\right)$ of $0.78 \mathrm{~g} \mathrm{~mL}^{-1}$ and melting point below $-78^{\circ} \mathrm{C}$ which \\ all compared well to the specifications of jet A-1.
}

\section{Introduction}

To maintain operational effectiveness, the armed services consume an enormous quantity of energy including liquid hydrocarbon fuels for air, land and sea vehicles. ${ }^{1}$ These liquid fuels are almost entirely derived from petroleum deposits found beneath the Earth's surface. ${ }^{2}$ The resulting crude oil from various parts of the world is processed, cracked, distilled and separated or 'cut' into the three most important fuel categories used by the military: aviation (jet), diesel, and gasoline. ${ }^{3}$ The US Navy has set ambitious goals of obtaining half of its energy from non-petroleum sources by $2020 .{ }^{4}$ We recently showed that fusel oil, pentanol isomers (isoamyl and 2-methyl-1-butyl alcohols) that are by-products from ethanol production, could be converted into ethers and acetals that combust properly in diesel engines (cetane numbers $>40$ ), Fig. $1 .^{5-7}$ Although the energy density of the latter oxygenated fuels were lower than diesel $\# 2$, such biodiesel could be a useful blendstock for non-tactical transportation purposes.

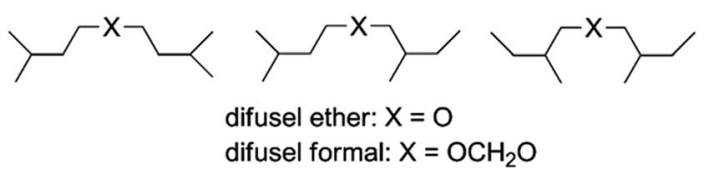

Fig. 1 Structures of biodiesel oxygenated fuels synthesized from fusel oil. $^{7}$

${ }^{a}$ Naval Air Warfare Center, Michelson Laboratory, Chemistry Division, China Lake, California 93555, USA

${ }^{b}$ University of North Texas Health Sciences Center, Department of Pharmacology and Neuroscience, Mass Spectrometry and Proteomics Laboratory, 3500 Camp Bowie Boulevard, Fort Worth, Texas 76107, USA. E-mail: matthew.davis@navy.mil

$\dagger$ Electronic supplementary information (ESI) available. See DOI: 10.1039/d0ra10386a
For military jet fuels such as JP-8 $\left(\geq 42.8 \mathrm{MJ} \mathrm{kg}^{-1}\right)$, a decrease in energy density is not acceptable so oxygenated fuels are generally unsuitable for military aviation. ${ }^{8,9}$ Attempting to prepare jet fuel from fusel oil would require different chemical reactions yielding hydrocarbons devoid of oxygen. There has been some recent technology referred to as alcohol-to-jet (ATJ) which has been developed by several research groups. ${ }^{10-14}$ In these two-step processes, fermentation alcohols (ethanol, 1butanol, isobutanol) are converted by high temperature $(>300$ ${ }^{\circ} \mathrm{C}$ ) dehydration over catalyst (silica/alumina) to alkene. In the second step, the alkenes are oligomerized over special catalysts (noble metals; Ziegler or acidic zeolites and resins) into ATJ synthetic paraffinic kerosene (ATJSPK), which are hydrocarbons ranging from 8-16 carbons with suitable properties for aircraft gas turbine engines. ${ }^{15}$

While these contemporary technologies would likely be useful to convert fusel oil to hydrocarbon liquids, there were early chemical studies in the characterization of fusel oil which appeared interesting in this respect. In 1844, Antoine Jérôme Balard described the preparation of 'amylene' and its oligomers (oligo(amylene), $n=0-2$ ) by heating a mixture of amyl alcohol from fusel oil and zinc chloride $\left(\mathrm{ZnCl}_{2}\right)$, Fig. $2 .{ }^{16-20}$

Although Balard had combustion analyses that supported the identity of the products, he did not report any details regarding the chemical apparatus, reagent stoichiometry,

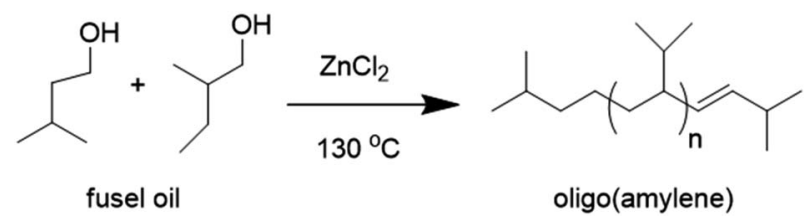

Fig. 2 The oligomerization of fusel oil with zinc chloride reported by Balard. 
conversion or percent yield of the products and did not have the benefit of modern chemical spectroscopy techniques. The reaction was mentioned in 1918 by Adams and coworkers who obtained little of the desired 'amylene' but a preponderance presumably of oligo(amylene) ${ }^{21}$ Although a complex product mixture was anticipated, we decided to reinvestigate Balard's reaction of fusel oil and zinc dihalides and this brief report will describe our preliminary results in isolating and characterizing the hydrocarbon products generated.

\section{Experimental}

\section{Materials and methods}

CAUTION! The zinc chloride and zinc bromide salts are both toxic to humans when ingested. ${ }^{22,23}$ Operators should use all appropriate personal protective equipment (gloves, face shield, laboratory apron, fume cupboard, etc.) when handling these substances. Crude fusel oil was obtained from the Archer Daniels Midland Company and contained $\sim 13 \mathrm{wt} \%$ water and 7 vol\% ethanol. Anhydrous zinc bromide and anhydrous zinc chloride were obtained from TCI America. Column chromatography was performed on silica gel (60 $\AA, 75-200 \mu \mathrm{m})$. Analytical thin-layer chromatography (TLC) was performed on Merck silica gel $60 \mathrm{~F}_{254}$ aluminum-backed plates. Visualization of TLC was by a UV light, $10 \mathrm{wt} \%$ phosphomolybdic acid $\left(\mathrm{H}_{3} \mathrm{PMo}_{12} \mathrm{O}_{40}\right)$ in EtOH (PMA stain) and $0.75 \mathrm{wt} \%$ potassium permanganate $\left(\mathrm{KMnO}_{4}\right)$ in $\mathrm{H}_{2} \mathrm{O}\left(\mathrm{KMnO}_{4}\right.$ stain). Details of additional methods to analyze the properties of the oligo(amylene) product including gas chromatography-mass spectrometry (GC-MS), bomb calorimetry, ignition quality test (IQT) and derived cetane number (DCN), elemental microanalysis, freezing point, flash point, density and kinematic viscosity and nuclear magnetic resonance (NMR) spectroscopy can be found in the ESI. $\dagger$

\section{Oligo(amylene) from crude fusel oil}

A borosilicate-glass, round-bottomed flask $(1 \mathrm{~L})$ equipped with magnetic stirring bar was filled with crude fusel oil (287.5 g, $2.84 \mathrm{~mol})$ followed by anhydrous zinc bromide $(320 \mathrm{~g}, 1.42 \mathrm{~mol}$, 0.5 equiv.). A Dean-Stark trap $(100 \mathrm{~mL})$ was equipped to the flask along with a high-efficiency condenser cooled by a recirculating coolant chiller $\left(6^{\circ} \mathrm{C}\right)$. The reaction was heated with a heating mantle (Variac® ${ }^{\circledR 5} \%$ ). The solids completely dissolved after a short time and the mixture was vigorously stirred. Once the internal temperature was sufficiently high $\left(\sim 180^{\circ} \mathrm{C}\right)$, a vigorous reflux was established. After the distillation/ collection of $\mathrm{H}_{2} \mathrm{O}$ appeared to cease $(85 \mathrm{~mL} ; 7 \mathrm{~h})$, the mixture was cooled to RT. The Dean-Stark trap was replaced with a distillation head and the reaction mixture was distilled at reduced pressure (10 Torr, Variac ${ }^{\circledR} 40 \%$ ) to obtain an unfractionated distillate $\left(80-120{ }^{\circ} \mathrm{C}, 134.89 \mathrm{~g}\right)$. The distillation pot contained the residual zinc bromide salt that was a slightly pinkish colored solid. The distillate was chromatographed through a short plug of silica gel eluting with hexanes to remove polar components and purify the hydrocarbon product (TLC: $R_{\mathrm{f}}$ $=0.9$ (hexanes); PMA or $\mathrm{KMnO}_{4}$ stain). The collected fractions containing hydrocarbon product were rotary evaporated (60 Torr, $40{ }^{\circ} \mathrm{C}$ bath) to remove the hexanes solvent. Then the residue was distilled at reduced pressure (10 Torr, Variac ${ }^{\circledR} 40 \%$ ) to obtain the final product as a clear, colorless mobile liquid (49 $\mathrm{g}, 24 \%)$.

\section{Results and discussion}

\section{Synthesis and characterization of Oligo(amylene)}

A ratio of crude fusel oil/zinc dihalide (2/1) was chosen as a starting point based on the work of Kuchkarev and Shuikin who prepared complexes between simple alcohols and zinc dihalides with this ratio. ${ }^{24}$ Heating these mixtures up to $\sim 180^{\circ} \mathrm{C}$ brought about azeotropic removal of water indicating a dehydrative reaction had occurred. The amount of water collected was roughly equivalent to sum from the 'wet' fusel oil and the stoichiometric dehydration of fusel alcohols. Afterwards, a liquid crude product mixture was distilled away from the zinc dihalide salts. Analysis by thin-layer chromatography (TLC) showed the crude product was composed primarily of a nonpolar component moving at the solvent front along with a polar component near the origin. There was little difference in product mixtures between zinc chloride or zinc bromide reactions by TLC analysis. However, product mixtures were cleanly separable by distillation from zinc bromide (mp $394{ }^{\circ} \mathrm{C}$ ), whereas zinc chloride $\left(\mathrm{mp} 275^{\circ} \mathrm{C}\right)$ tended to 'bump' into the condenser during the later stages of distillation owing to its lower melting temperature. ${ }^{25}$ For these reasons it was decided to focus on the reaction between zinc bromide and fusel oil which may not have been reported previously ${ }^{26} \mathrm{~A}$ general diagram of the process flow for the dehydration/oligomerization of fusel oil by zinc bromide and isolation of oligo(amylene) is shown and described below, Fig. 3 .

More thorough investigation of the crude product by gas chromatography-mass spectrometry (GC-MS) showed major peaks for isopentane (1.35 min; 2-methylbutane), unreacted isoamyl alcohol $(3.23 \mathrm{~min})$ and diisoamyl ether $(8.44 \mathrm{~min})$, Fig. 4. Although anticipated to be a major reaction pathway, halogenation of isoamyl alcohol, the primary component of fusel oil, was very minimal since only a trace of isoamyl bromide (4.25 $\mathrm{min}$ ) had formed. The only additional components of the reaction product were oligo(amylene) ( $n=0$, diamylene; $n=1$, triamylene; $n=2$, tetraamylene, etc.) that showed significant disproportionation and/or cracking $(5-20 \quad \mathrm{~min}){ }^{27,28}$ For

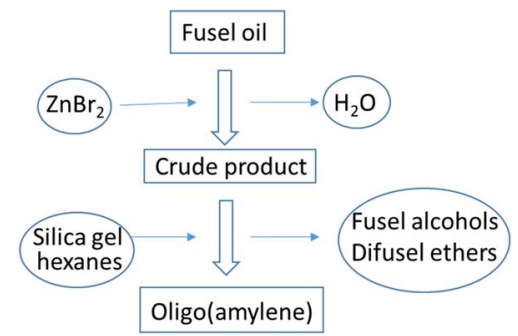

Fig. 3 Process flow diagram for the preparation of oligo(amylene) from fusel oil by zinc bromide catalysis. 


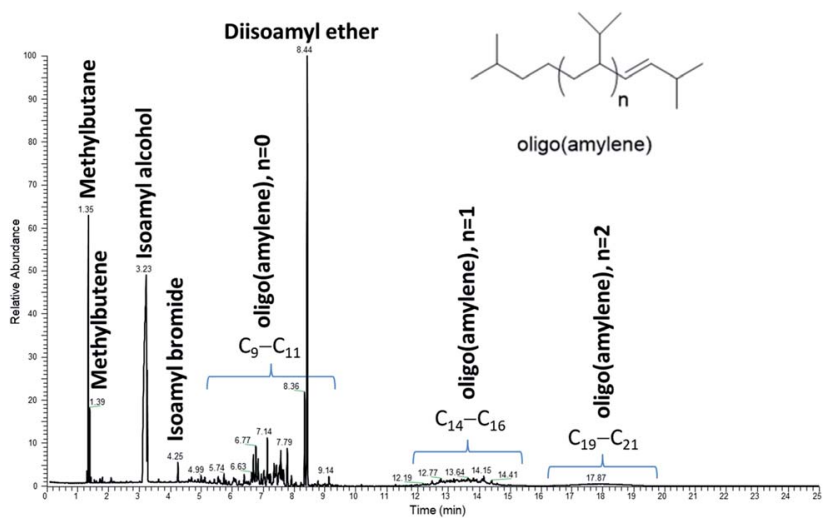

Fig. 4 GC-MS chromatogram (total ion current, $70 \mathrm{eV}$ ) of the crude product from the reaction of fusel oil and zinc bromide.

example, the isopentene isomer (1.39 min) was accompanied by a significant peak of isopentane peak (1.35 $\mathrm{min})$. It was expected that isoamyl alcohol would undergo dehydration from the zinc bromide catalyst leading to isopentene (3-methyl-1-butene). Furthermore, one would anticipate 3-methyl-1-butene to isomerize to the more thermodynamically stable 2-methyl-2-butene under the vigorous conditions of the reaction. ${ }^{29}$ However, it is difficult to conclude whether peak 1.39 min is either methylbutene isomer since their mass spectral fragmentation patterns are virtually identical. ${ }^{30}$ The oligo(amylene) tended to be mixtures complicated by elimination or addition of one carbon fragment. Thus, the diamylene had $\mathrm{C}_{9}$ and $\mathrm{C}_{11}$ portions, the triamylene had $\mathrm{C}_{14}$ and $\mathrm{C}_{16}$ and so on up to octaamylene $\left(+\mathrm{C}_{29}\right.$ and $\mathrm{C}_{31}$ ) which appeared to be the heaviest oligomer formed under the reaction conditions. The oligomers were composed of many peaks most likely owing to isomers.

Of the oligo(amylene), the diamylene fraction was in greatest concentration, followed by triamylene and the heavier $n=2-4$ were in lowest concentration based on the GC-MS total ion chromatogram. The mass spectrum of triamylene is illustrative of the fragmentation pattern of these hydrocarbons, Fig. 5. The base peak at $m / z 71\left(\mathrm{C}_{5} \mathrm{H}_{11}{ }^{+}\right)$indicated a hydrocarbon as many small branched hydrocarbons share this base peak. ${ }^{31}$ The fragments are also separated by $m / z 14$ mass units which is the characteristic carbenium ion fragmentation found in hydrocarbons. ${ }^{32,33}$ Owing to the high degree of branching likely present in the oligo(amylene), the spectrum does not have the smooth exponential decrease in fragment peak height typical of linear hydrocarbons. Although the $\mathrm{M}^{+}$at 210 is present which fits well with triamylene $(n=1)$, there were $m / z 224$ ion $(n=1+$ $\left.\mathrm{CH}_{2}\right)$ and $196\left(n=1-\mathrm{CH}_{2}\right)$ from cracking processes.

Attempts to separate the polar and non-polar components of the crude product mixture with the process equipment on hand failed as the two components appeared to co-distill at atmospheric or reduced pressure. Similar difficulties were experience by others in the fractional distillation of related mixtures of methyl tert-butyl ether and isobutene dimers. ${ }^{34,35}$ Therefore, the crude product mixture was fractionated by liquid chromatography on silica gel. The fast moving, non-polar component was cleanly separated by this process and the proton and carbon- 13 nuclear magnetic resonance spectrum showed that it was the oligo(amylene), Fig. 6. The spectrum was free from signals related to fusel alcohols and difusel ethers $(\sim 3.5-3.0 \mathrm{ppm}) .^{7}$ The spectrum was very simple with a less intense alkene region at 5.5-4.75 ppm and a dominant aliphatic hydrocarbon region 2.0-0.75 ppm with an integral ratio of 0.04 consistent with

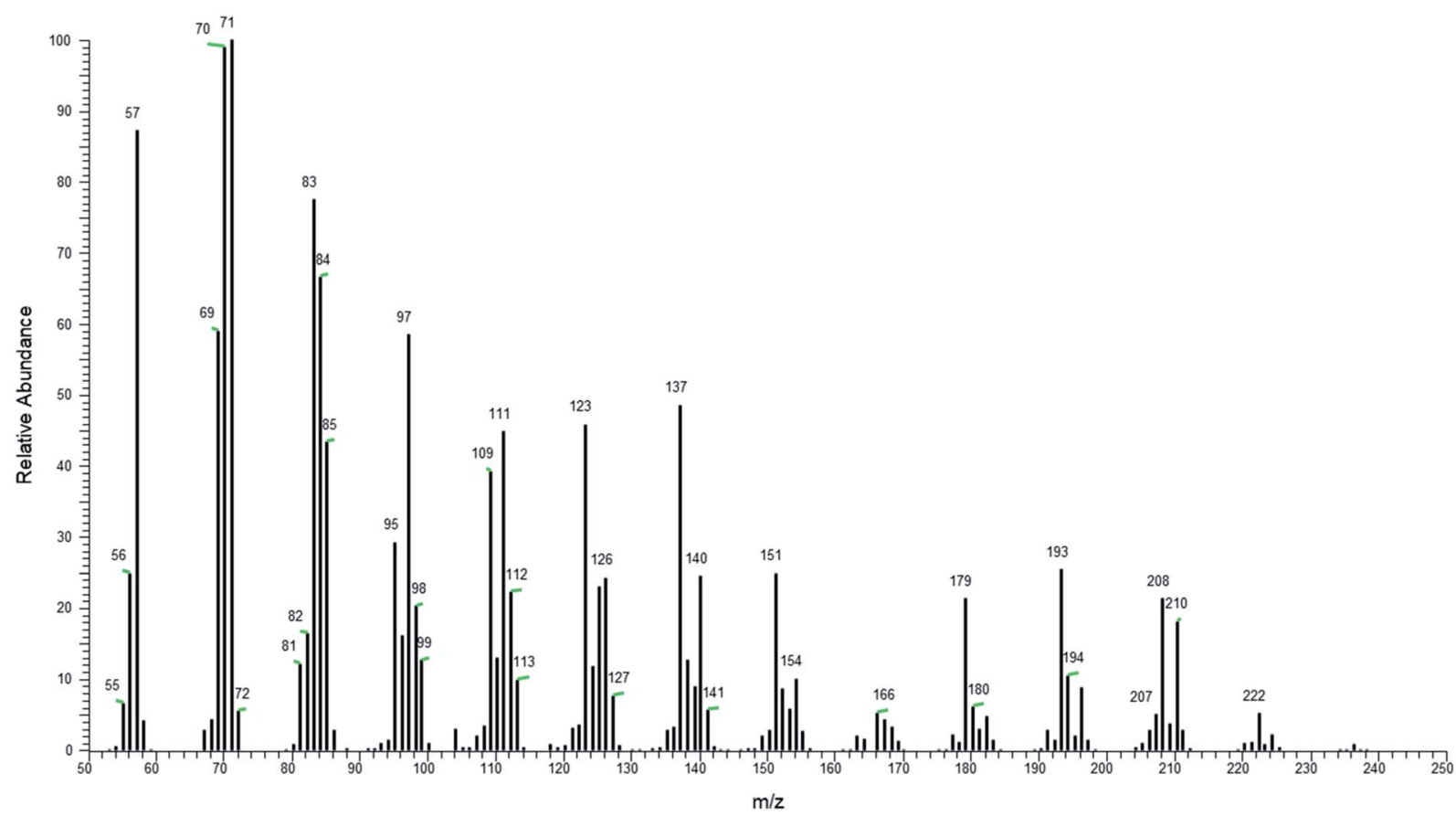

Fig. 5 Averaged electron ionization mass spectrum (12 eV) of the triamylene domain $\left(\mathrm{C}_{15} \mathrm{H}_{30}\right)$. 


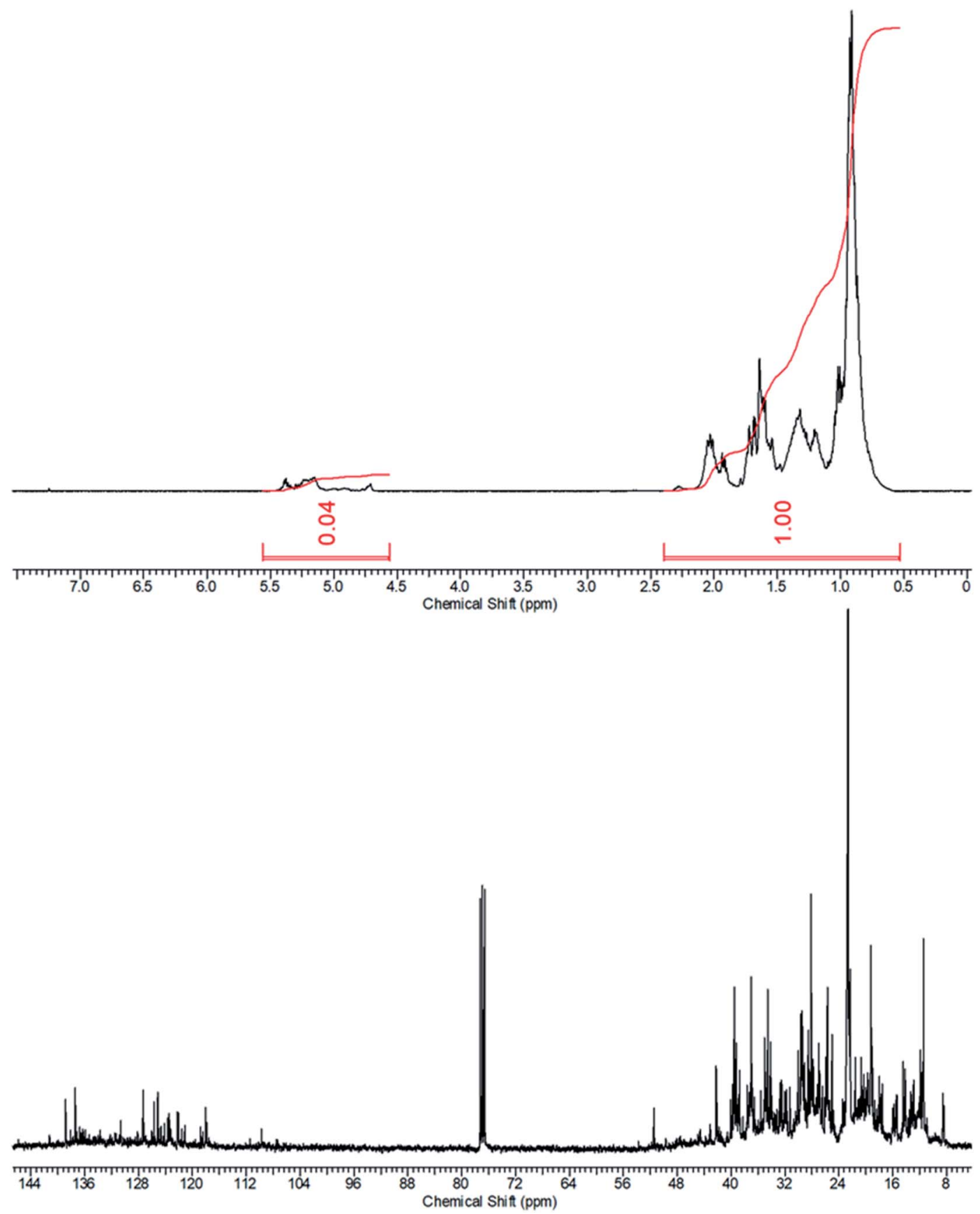

Fig. 6 Proton and carbon-13 NMR spectra of the purified oligo(amylene) product in deuterochloroform at room temperature.

a product having one double bond. The carbon-13 spectrum was also relatively simple with an alkene region 140-115 ppm and an aliphatic region 50-8 ppm. The relatively small integrative value of the alkene region in the proton spectrum and the relatively large area of the alkene region in the carbon-13 spectra indicated that the alkenes of the oligo(amylene) were highly substituted (e.g. tertiary).

Elemental composition ( $\mathrm{C}$ and $\mathrm{H}$ ) of the oligo(amylene) by elemental microanalyses were both within the commonly accepted margin of error $(<0.4 \%)$ for the structure as drawn, Table 1 . The microanalyses also proved that the hydrocarbon was free of bromine and verified the GC-MS data which lacked signature molecular ions for alkyl bromides and/or alkyl polybromides and their bromine isotopes. ${ }^{36}$ As further proof that the solvent from chromatography had been completely removed, GC-MS analysis corroborated the absence of hexanes

Table 1 Carbon and hydrogen microanalyses results for the purified oligo(amylene)

\begin{tabular}{|c|c|c|c|c|c|c|}
\hline \multirow{2}{*}{$\begin{array}{l}\text { Molecular } \\
\text { formula }\end{array}$} & \multicolumn{3}{|c|}{ Carbon (\%) } & \multicolumn{3}{|c|}{ Hydrogen (\%) } \\
\hline & Theory & Found & Difference & Theory & Found & Difference \\
\hline$\left(\mathrm{C}_{5} \mathrm{H}_{10}\right)_{n}$ & 85.63 & 85.53 & 0.1 & 14.37 & 14.19 & 0.18 \\
\hline
\end{tabular}




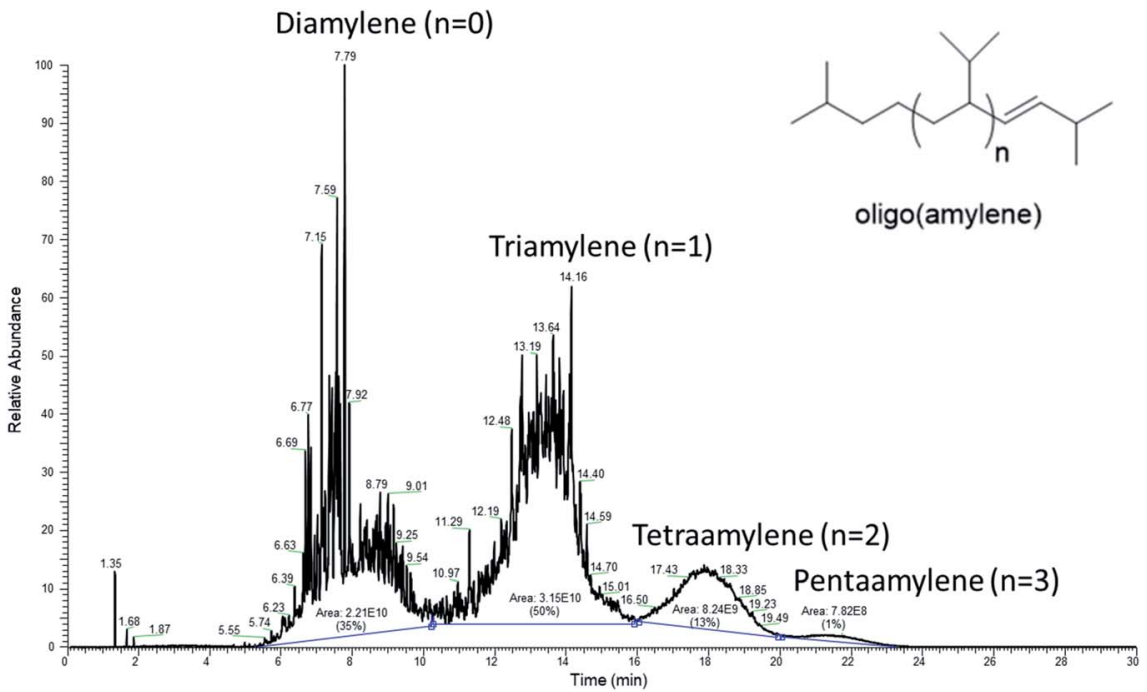

Fig. 7 GC-MS chromatogram (total ion current, $70 \mathrm{eV}$ ) of the purified oligo(amylene) product.

in the post-chromatographic, oligo(amylene) product, Fig. 7. As anticipated, the volatile methylbutane and methylbutene were lost but lighter diamylenes were not removed during the hexanes evaporation. An estimate of the oligo(amylene) distribution based on the GC-MS total ion chromatogram was: $n=$ 0 (35\%), $n=1(50 \%), n=2(13 \%)$, and $n=3(1 \%)$. Interestingly, this product profile matched the original results of Balard who isolated only oligo(amylene) $(n=0-2) \cdot{ }^{16}$ The yield of oligo(amylene) produced based on fusel oil input was calculated at $\sim 25 \%$ which was typical after a series of runs using either zinc chloride or zinc bromide. This yield did not take into account the mass of unreacted isoamyl alcohol nor the by-product diisoamyl ether which were not isolated during this brief study. Although a cold condenser was used during the reaction, it was likely that some 2-methylbutene isomers may have been lost to evaporation from the reactor system. In runs that were conducted for longer periods of time in the effort to achieve a higher yield of oligo(amylene), the yield did not increase but the oligomer distribution was shifted to higher number repeat units.

It was fortuitous that the reaction conditions gave oligo(amylene) containing a preponderance of triamylene since it was hypothesized that this fraction would have fuel properties closest to kerosene type fuels (e.g. diesel and jet). The purified oligo(amylene) was fractionated by one distillation at reduced pressure which gave a single fraction that was primarily triamylene (oligo(amylene) $n=1$ ) by GC-MS analysis, Fig. 8 . The lighter diamylene fraction was lost during the reduced pressure distillation while the distillation pot residue was composed of the less volatile oligo(amylene) $(n=2-4)$. In one run where the

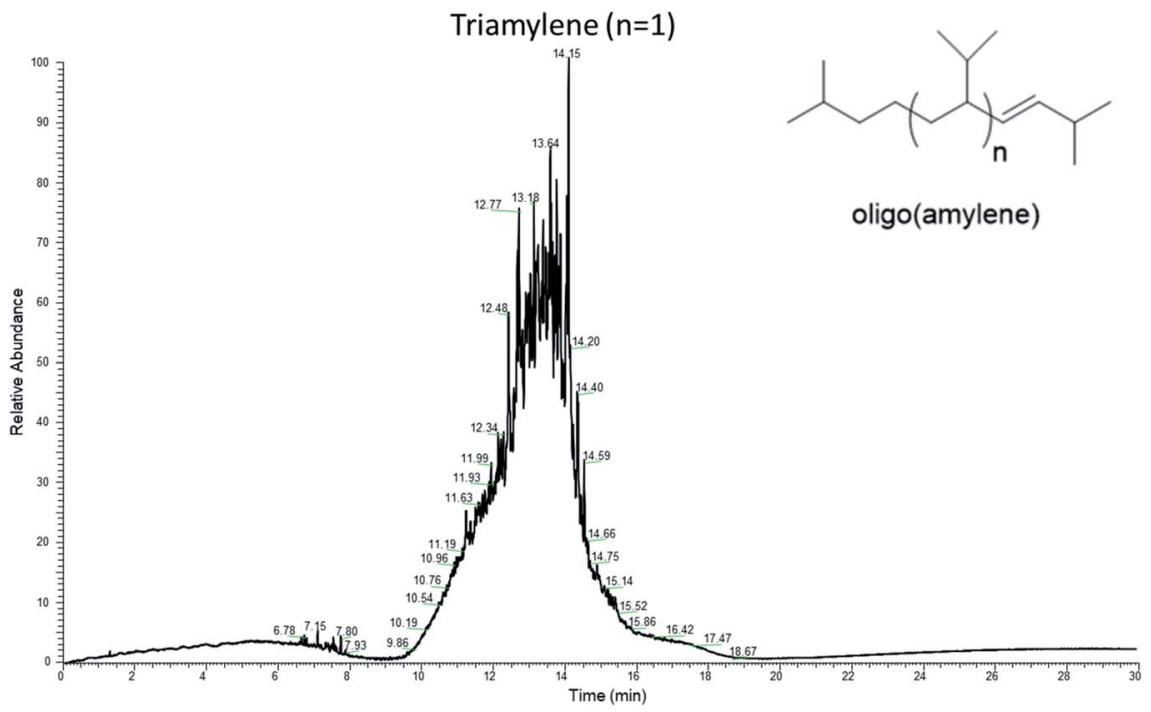

Fig. 8 GC-MS chromatogram (total ion current, $70 \mathrm{eV}$ ) of the triamylene which was purified from the oligo(amylene) mixture by single fractional distillation. 

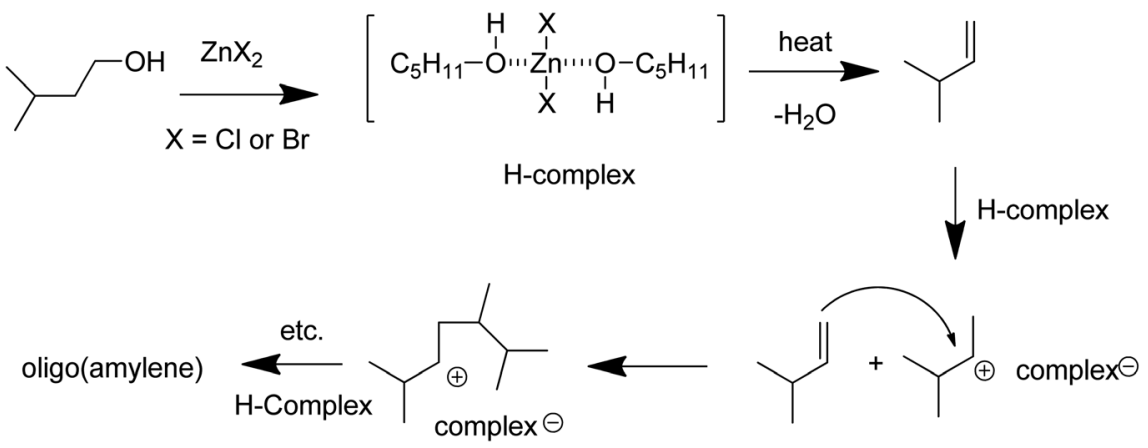

Fig. 9 Possible mechanism for the formation of oligo(amylene) from fusel oil and zinc dihalide salts.

reaction mixture was allowed to continue for a longer period of time, bulk quantities of the higher boiling tetraamylene were isolated by fractional distillation ( $\left.\mathrm{ESI}_{\dagger}^{\dagger}\right)$.

Zinc dihalides are known to form complexes with alcohols which are acidic in nature and such a complex would likely form between fusel alcohols and zinc bromide. ${ }^{37}$ The presence of isoamylene in the crude product mixture provides evidence in support of a possible mechanism for the formation of oligo(amylene) involving dehydration/polymerization of isoamyl alcohol, Fig. 9. Other researchers have shown that zinc chloride can bring about dehydration of sorbitol into isosorbide among other products. ${ }^{38}$ The isoamylene could then react with the acidic Lewis acid complex (H-complex) to form cationic intermediates which would bring about polymerization. ${ }^{39-41}$ The uncomplexed zinc dihalide could also polymerize the isoamylene since Antsus and Petrov made oligo(propene) by heating propene with zinc chloride under pressure. ${ }^{42}$

After removing the crude product from the reaction mixture, the zinc bromide was only contaminated by a small quantity of higher boiling oligo(amylene). The impure zinc bromide was effective in transforming a second portion of fusel oil into oligo(amylene) although the yield decreased slightly. The zinc bromide was readily purified from organic contamination by liquid phase extraction with water followed by azeotropic drying. ${ }^{43}$ We continue to study the recovery and recycling of zinc bromide for the dehydration/oligomerization of fusel oil and will report those details later. Since dehydration of the alcohol by zinc dihalide is believed to be the initial step of the process, the reaction conditions were altered to attempt the isolation of this product. Thus, anhydrous isoamyl alcohol was carefully added dropwise into stirred molten zinc chloride. However, the liquid that immediately distilled away was simply the unchanged alcohol.

\section{Preliminary fuel property analysis of the triamylene (oligo(amylene) $n=1$ )}

Since the triamylene (oligo(amylene) $n=1$ ) was readily isolated by one distillative fractionation of the oligo(amylene) mixture, the preliminary fuel property testing was carried out on this oligo(amylene) fraction. The boiling range, flashpoint, net heating value, cetane number, viscosity, density and freezing point of the triamylene were compared with those specifications for gasoline, diesel (D\#2) and jet fuel (A-1), Table $2 .{ }^{44-46}$ The general ranges of carbon atoms for these reference fuels show that triamylene $\left(\sim \mathrm{C}_{15}\right)$ falls towards the kerosene range (D\#2 and A-1). ${ }^{47}$ Although, it must be mentioned that gasoline, diesel and jet fuel are mixtures not only of alkanes but may contain up to $50 \%$ of cycloalkanes and aromatic hydrocarbons. Even when cooled to $-78{ }^{\circ} \mathrm{C}$, the triamylene remained a clear, mobile liquid when shaken and could be poured or even pipetted with a standard laboratory Pasteur pipette. Thus the triamylene had a low freezing point well below the specifications of the

Table 2 Selected fuel properties of triamylene compared to specifications of gasoline, diesel \#2 and jet A-1

\begin{tabular}{|c|c|c|c|c|c|}
\hline \multicolumn{2}{|l|}{ Fuel Property } & Gasoline $^{a}$ & Diesel $\# 2^{b}$ & Jet A-1 ${ }^{c}$ & Triamylene \\
\hline \multicolumn{2}{|l|}{ Carbon atoms } & $5-13$ & $10-25$ & $9-13$ & $14-16$ \\
\hline \multicolumn{2}{|l|}{ Boiling range $\left({ }^{\circ} \mathrm{C}\right)$} & $50-200$ & $200-300$ & $140-280$ & $50-135$ \\
\hline \multicolumn{2}{|l|}{ Net heating value $\left(\mathrm{kJ} \mathrm{g}^{-1}\right)$} & 42.8 & 42.7 & 42.8 & 43.94 \\
\hline \multicolumn{2}{|l|}{ Cetane number } & $17.6^{d}$ & $\geq 40$ & $48^{e}$ & 31.9 \\
\hline Viscosity $\left(\mathrm{mm}^{2} \mathrm{~s}^{-1}\right)\left({ }^{\circ} \mathrm{C}\right)$ & 40 & - & $1.9-4.1$ & - & 1.75 \\
\hline Density $\left(\mathrm{g} \mathrm{mL} \mathrm{m}^{-1}, 15^{\circ} \mathrm{C}\right)$ & & $0.71-0.78^{g}$ & 0.85 & $0.78-0.84$ & 0.78 \\
\hline Freezing point $\left({ }^{\circ} \mathrm{C}\right)$ & & $-60^{h}$ & $-12^{i},-40^{j}$ & $\geq-47$ & $<-78$ \\
\hline
\end{tabular}

${ }^{a}$ Ref. $44 .{ }^{b}$ Ref. $45 .{ }^{c}$ Ref. $46 .{ }^{d}$ 2,2,4-Trimethylpentane (ref. 50). ${ }^{e}$ Ref. $49 .{ }^{f}$ Ref. $52 .{ }^{g}$ Ref. $53 .{ }^{h}$ Ref. $48 .{ }^{i}$ Cloud point (ref. 49). ${ }^{j}$ Pour point (ref. 49 ). 
standard petroleum-based fuels, particularly aviation and diesel. ${ }^{4,49}$ The flash point of triamylene was $38^{\circ} \mathrm{C}$ which is also the minimum for A-1 but somewhat less than $\mathrm{D \# 2}\left(55^{\circ} \mathrm{C}\right)$ and much higher than gasoline $\left(-43^{\circ} \mathrm{C}\right)$. The atmospheric pressure distillation of triamylene was over a range of $50-135{ }^{\circ} \mathrm{C}$ which was similar to the range for gasoline $\left(50-200{ }^{\circ} \mathrm{C}\right)$ but lower than the boiling ranges of $\mathrm{D} \# 2$ and $\mathrm{A}-1$. The net calorific value of the triamylene fraction $\left(43.96 \mathrm{~kJ} \mathrm{~g}^{-1}\right)$ had $\sim 3 \%$ greater energy than the specifications of the three petroleum reference fuels $(42.8 \mathrm{~kJ}$ $\mathrm{g}^{-1}$ ). The cetane number of the triamylene (31.9) did not meet the cetane number criterion for $\mathrm{D} \# 2$ (40) or the related kerosene A-1 (48). ${ }^{49}$ However, the cetane number of the triamylene was almost double that of the ideal gasoline hydrocarbon 2,2,4-trimethylpentane (17.6). ${ }^{50}$ Although the precise molecular structure of the triamylene was not determined in this study, the hydrocarbon is undoubtedly highly branched given the proposed mechanism of formation. Thus, it was not surprising that the cetane number of the triamylene was only 31.9 since branching in alkanes increases ignition delay under compression ignition conditions (e.g. knocking). For example, the highly branched alkane 2,3,4,5,6,7,8-heptamethylnonane $\left(\mathrm{C}_{16}\right)$ has a cetane number of $15 .^{51}$ The viscosity $\left(40^{\circ} \mathrm{C}\right)$ of the triamylene $\left(1.75 \mathrm{~mm}^{2} \mathrm{~s}^{-1}\right)$ was slightly below the specifications for $\mathrm{D \# 2}$ (1.9-4.1 $\left.\mathrm{mm}^{2} \mathrm{~s}^{-1}\right)$. The triamylene $\left(2.53 \mathrm{~mm}^{2} \mathrm{~s}^{-1}\right)$ was more viscous than gasoline $\left(0.72 \mathrm{~mm}^{2} \mathrm{~s}^{-1}\right)$ when measured at $20{ }^{\circ} \mathrm{C}^{52}$ However, the viscosity of the triamylene $\left(7.85 \mathrm{~mm}^{2} \mathrm{~s}^{-1}\right)$ was approximately equivalent to the specifications of $\mathrm{A}-1\left(8 \mathrm{~mm}^{2}\right.$ $\left.\mathrm{s}^{-1}\right)$ at $-20{ }^{\circ} \mathrm{C}$. The density of the triamylene $\left(0.78 \mathrm{~g} \mathrm{~mL}^{-1}\right)$ was less than the specification for $\mathrm{D} \# 2\left(0.85 \mathrm{~g} \mathrm{~mL}^{-1}\right)$ at $15^{\circ} \mathrm{C}$ but was within the range limits for both $\mathrm{A}-1$ and gasoline. ${ }^{53}$ The triamylene $\left(43.94 \mathrm{~kJ} \mathrm{~g}^{-1}\right)$ had $8.5 \%$ more energy and nearly double the cetane number of isoamyl alcohol $\left(37 \mathrm{~kJ} \mathrm{~g}^{-1}\right.$ and 18.4, respectively), the major alcohol found in fusel oil from which it was made. ${ }^{54,55}$

\section{Conclusions}

Heating mixtures of fusel oil with zinc chloride or zinc bromide does produce the deoxygenated hydrocarbon oligo(amylene) as reported by Balard though the yield was only $\sim 25 \%$. The major product from the reaction was diisoamyl ether from etherification of isoamyl alcohol, the major component of fusel oil. ${ }^{56}$ The reaction procedure was uncomplicated and although zinc chloride or zinc bromide were employed stoichiometrically, the salts could be recovered and recycled quantitatively. Unlike noble metal catalyst employed in several ATJ processes, the zinc salts are inexpensive since they are derived from a 'coinage' metal. ${ }^{57}$ The zinc salts were robust and unaffected by the presence of water in the fusel oil. Although the ether co-product may be useful as a diesel oxygenate, it was not desirable for our purposes. $^{7}$ The process was demonstrated at modest scale to prepare oligo(amylene) $(100 \mathrm{~mL})$ but the challenges of isolating the hydrocarbon will require further study and optimization. The triamylene fraction of the oligo(amylene) $(n=1)$ is less useful for compression ignition engines since the cetane number was lower than specifications for US diesel \#2. The triamylene had net calorific value slightly better than the minimum specifications for diesel \#2, jet A-1 and gasoline. Other fuel property data for the triamylene such as flash point, boiling range, viscosity, freezing point and density compared reasonably well to those of jet A-1. Thus, the triamylene could be a fungible blendstock for gas turbine engine fuels. ${ }^{58,59}$ By controlling the degree of oligomerization, the fusel oil can be converted into fuels or lubricants. The heavier oligomers which are less desirable as transportation fuels could be useful base oils for lubricant fluids, greases and hydraulic fluids. The oligo(amylene) could be used in crude form for burning in less discriminating engines such as boiler units and generators that operate on Class C2 fuel oil. ${ }^{60}$ The oligo(amylene) described here was made in batches but experiments are currently underway to run the process continuously for increased throughput.

\section{Conflicts of interest}

There are no conflicts to declare.

\section{Acknowledgements}

This research was supported by the In-house Laboratory Independent Research (ILIR) program of the Office of Naval Research, US Department of the Navy. Thanks to: the UNTHSC Graduate School of Biomedical Sciences for the purchase of the GC-MS, The Welch Foundation for endowment BK-0031 to L.P., Timothy Kidwell (SWRI) for assistance with the cetane number analyses, Mary Ray (NAWCWD Technical Library) for collecting several of the literature citations, Michelle Wade and Tom Czibovic (NAWCWD) for their assistance in obtaining the sample analyses, various materials and supplies, and Jose Leboriero Hernandez and Sean Miller of the Archer Daniels Midland Company for helpful discussions about fusel oil and a generous sample.

\section{References}

1 Office of the Assistant Secretary of Defense for Energy, Installations and Environment, Annual Energy Management and Resilience (AEMR) Report, Department of Defense, Washington D.C., 2017, available at: http:// www.acq.osd.mil/eie/Downloads/IE/.

2 B. P. Tissot and D. H. Welte, Petroleum Formation and Occurrences: A New Approach to Oil and Gas Exploration, Springer Link, New York, 1978.

3 W. L. Leffler, Petroleum Refining in Nontechnical Language, PennWel, Tulsa, 4th edn, 2000.

4 S. Scherer, U.S. Navy 'Green Fleet' fills up with Italian-made biofuel, Reuters, 2016, https:/www.reuters.com/article/ususa-defense-italy-biofuels-idUSKCNOZ22EV.

5 A. D. Webb and J. L. Ingraham, Fusel oil, Adv. Appl. Microbiol., 1963, 5, 317-353, DOI: 10.1016/S0065-2164(08) 70014-5.

6 R. C. Schupphaus, On the alcohols of fusel oil, J. Am. Chem. Soc., 1892, 14, 45-60, DOI: 10.1021/ja02123a005. 
7 L. B. Baldwin, M. C. Davis and J. -D. Woodroffe, Potential oxygenated biofuels synthesized from fusel pentanols, Fuel, 2020, 270, 117505, DOI: 10.1016/j.fuel.2020.117505.

8 J. I. Hileman, R. W. Stratton and P. E. Donohoo, Energy content and alternative jet fuel viability, J. Propul. Power, 2010, 26, 1184-1196, DOI: 10.2514/1.46232.

9 MIL-DTL-83133E, Detail Specification: turbine fuel, aviation, kerosene type, JP-8 (NATO F-34), NATO F-35, and JP-8+100 (NATO F-37), 11 April 2008.

10 M. El-Halwagi, K. R. Hall and H. D. Spriggs, Integrated biofuel processing system, to Byogy Renewables Inc. and Texas A\&M University System, US Pat., US8802905B2, 12 August 2014.

11 M. E. Wright, B. G. Harvey and R. L. Quintana, Diesel and jet fuels based on the oligomerization of butane, to US Secretary of Navy, US Pat., 9732295B1, 15 August 2017.

12 M. A. Lilga, R. T. Hallen, K. O. Albrecht, A. R. Cooper, J. G. Frye and K. K. Ramasamy, Systems and processes for conversion of ethylene feedstocks to hydrocarbon fuels, to Battelle Memorial Institute, Inc., US Pat., 9663416B2, 30 May 2017.

13 M. Peters and J. Taylor, Renewable jet fuel blendstock from isobutanol, to Gevo, European Patent 2566830B1, 22 March 2017.

14 M. A. Díaz-Perez and J. C. Serrano-Ruiz, Catalytic production of jet fuels from biomass, Molecules, 2020, 25, 802, DOI: 10.3390/molecules25040802.

15 W. C. Wang, L. Tao, J. Markham, Y. Zhang, E. Tan, L. Batan, E. Warner and M. Biddy, Review of Biojet Fuel Conversion Technologies, National Renewable Energy Laboratory (NREL), United States, 2016, DOI: 10.2172/1278318.

16 A. J. Balard, Premier mémoire sur l'alcool amylique, Adv. Appl. Microbiol., 1844, 12, 294-330.

$17 \mathrm{~J}$. Walther, Zur einwirkung des chlorzinks auf amylalkohol, J. Prakt. Chem., 1899, 59, 41-45, DOI: 10.1002/ prac.18990590104.

18 A. Wischnegradsky, Ueber verschiedene amylene und amylalcohole, Justus Liebigs Ann. Chem., 1878, 190, 328366, DOI: 10.1002/jlac.18781900307.

19 A. Étard, Sur la préparation de l' amyléne, C. R. Hebd. Seances Acad. Sci., 1878, 86, 488-490.

20 J. Snow, Further remarks on amylene (Part 1), Medical Times \& Gazette, 1857, 14, 332-334.

21 R. Adams, O. Kamm and C. S. Marvel, Organic chemical reagents. II. Amylene, tertiary amyl alcohol, J. Am. Chem. Soc., 1918, 40, 1950-1955, DOI: 10.1021/ja02245a020.

22 L. M. Plum, L. Rink and H. Haase, The essential toxin: impact of zinc on human health, Int. J. Environ. Res. Public Health, 2010, 7, 1342-1365, DOI: 10.3390/ijerph7041342.

23 G. J. Fosmire, Zinc toxicity, Am. J. Clin. Nutr., 1990, 51, 225227, DOI: 10.1093/ajcn/51.2.225.

24 A. B. Kuchkarev and N. I. Shuikin, Complex compounds of metal halides with alcohols, Bull. Acad. Sci. USSR, Div. Chem. Sci., 1954, 3, 397-403, DOI: 10.1007/BF01167816.

25 T. B. Lloyd, Zinc compounds, in Concise encyclopedia of chemical technology, ed. M. Grayson, John Wiley \& Sons, New York, 3rd edn, 1985, p. 1279.
26 R. A. Gossage, Zinc (II) bromide: an overview of its solution chemistry and recent applications in synthesis, Curr. Org. Chem., 2006, 10, 923-936, DOI: 10.2174/ 138527206777435544.

27 M. Granollers, J. F. Izquierdo, J. Tejero, M. Iborra, C. Fité, R. Bringué and F. Cunill, Isoamylene trimerization in liquid-phase over ion exchange resins and zeolites, Ind. Eng. Chem. Res., 2010, 49, 3561-3570, DOI: 10.1021/ ie901382p.

28 D. E. Murphy and P. C. Lane Jr, Oligomerization of 2-Methyl2-butene in Sulfuric and Sulfuric-Phosphoric Acid Mixtures, Ind. Eng. Chem. Prod. Res. Dev., 1975, 14, 167-171, DOI: 10.1021/i360055a008.

29 R. H. Ewell and P. E. Hardy, Isomerization equilibrium among the branched chain pentenes, J. Am. Chem. Soc., 1941, 63, 3460-3465, DOI: 10.1021/ja01857a059.

30 https:/www.restek.com/compound/view/563-45-1/3-Methyl1-butene and https://www.restek.com/compound/view/51335-9/2-Methyl-2-butene, accessed 9 October 2020.

31 E. D. McCarthy, J. Han and M. Calvin, Hydrogen atom transfer in mass spectrometric fragmentation patterns of saturated aliphatic hydrocarbons, Anal. Chem., 1968, 40, 1475-1480, DOI: 10.1021/ac60266a021.

32 K. Biemann, Mass Spectrometry: Organic Chemical Applications, McGraw-Hill: New York, 1962.

33 J. Gross, Mass Spectrometry, Springer-Verlag, Berlin, 2nd edn, 2011, ch. 6, pp. 249-350, DOI: 10.1007/978-3-642-10711-5_6.

34 M. L. Honkela and A. O. I. Krause, Influence of polar components in the dimerization of isobutene, Catal. Lett., 2003, 87, 113-119, DOI: 1011-372X/03/0400-0113/0.

35 M. De Girolamo, M. Lami, M. Marchionna, E. Pescarollo, L. Tagliabue and F. Ancillotti, Liquid-phase etherification/ dimerization of isobutene over sulfonic acid resins, Ind. Eng. Chem. Res., 1997, 36, 4452-4458, DOI: 10.1021/ ie9700932.

36 T. O. Nicolescu, Interpretation of mass spectra in Mass Spectrometry, ed. M. Aliofkhazraei, IntechOpen, 2017, DOI: 10.5772/intechopen.68595.

37 A. B. Kuchkarev, Molecular compounds of zinc chloride and alcohols, Zh. Obshch. Khim., 1952, 22, 1127-1132.

38 J. Li, A. Spina, J. A. Moulijin and M. Makkee, Sorbitol dehydration into isosorbide in a molten salt hydrate medium, Catal. Sci. Technol., 2013, 3, 1540-1546, DOI: 10.1039/C3CY20809E.

39 J. F. Norris and J. M. Joubert, The polymerization of the amylenes, J. Am. Chem. Soc., 1927, 49, 873-886, DOI: 10.1021/ja01402a032.

40 P. L. Cramer and J. M. Cambell, Synthetic decanes as highantiknock fuels, Ind. Eng. Chem., 1937, 29, 234-237, DOI: 10.1021/ie50326a028.

41 L. Schmerling and V. N. Ipatieff, The mechanism of the polymerization of alkenes, Adv. Catal., 1950, 2, 21-80, DOI: 10.1016/S0360-0564(08)60374-0.

42 L. I. Antsus and A. D. Petrov, Mechanism of the catalytic polymerization of propene under pressure, Russ. Chem. Bull., 1956, 5, 1153-1159, DOI: 10.1007/BF01177369. 
43 P. N. Davey and C. L. Tse, Reactions using Lewis acids, World Patent WO200069777A1, to Quest International B. V., 23 November 2000.

44 J. Bacha, J. Freel, A. Gibbs, L. Gibbs, G. Hemighaus, K. Hoekman, A. Gibbs, M. Ingham, L. Jossens, D. Kohler, D. Lesnini, J. McGeehan, M. Nikanjam, E. Olsen, R. Organ, B. Scott, M. Sztenderowicz, A. Tiedemann, C. Walker, J. Lind, J. Jones, D. Scott and J. Mills, Diesel fuels technical review, Chevron Corporation, 2007, https:// www.chevron.com/-/media/chevron/operations/documents/ diesel-fuel-tech-review.pdf, accessed 12 October 2020.

45 Jet $A$ or Jet A-1 Aviation Fuel, Product specification sheet, Petrostar Incorporated, May, 2014, www.petrostar.com, accessed 12 October 2020.

46 ASTM D4814-20a, Standard Specification for Automotive Spark-Ignition Engine Fuel, ASTM International, West Conshohocken, Pennsylvania, USA, 2020, DOI: 10.1520/ D4814-20A.

47 J. Holladay, Z. Abdullah and J. Heyne, Sustainable Aviation Fuel: Review of Technical Pathways, Office of Energy Efficiency \& Renewable Energy, US Department of Energy, ch. 2, pp. 7-16, September 2020, https://www.energy.gov/ sites/prod/files/2020/09/f78/beto-sust-aviation-fuel-sep2020.pdf.

48 D. Diemand, Automotive fuels at low temperatures, U.S. Army Cold Regions Research and Engineering Laboratory, Hanover, New Hampshire, Cold Regions Technical Digest 91-2, 1991.

49 J. T. Edwards, Reference jet fuels for combustion testing, 55th American Institute for Aeronautics and Astronautics, Aerospace Sciences Meeting, Grapevine, Texas, 2017, DOI: 10.2514/6.2017-0146.

50 A. D. Puckett and B. H. Caudle, Ignition qualities of hydrocarbons in the diesel fuel boiling range, Washington, DC: U.S. Department of the Interior, Bureau of Mines Information Circular 7474, 1948.
51 S. M. Heck, H. O. Pritchard and J. F. Griffiths, Cetane number vs. structure in paraffin hydrocarbons, J. Chem. Soc., Faraday Trans., 1998, 94, 1725-1727, DOI: 10.1039/ A800861B.

52 D. J. Luning Prak, J. S. Cowart and P. C. Trulove, Density, viscosity, speed of sound, bulk modulus, and surface tension of binary mixtures of $n$-heptane $+2,2,4$ trimethylpentane at $(293.15$ to 338.15$) \mathrm{K}$ and $0.1 \mathrm{MPa}, J$. Chem. Eng. Data, 2014, 59, 3842-3851, DOI: 10.1021/ je5007532.

53 ASTM D4052-18 Standard test method for density, relative density, and API gravity of liquids by digital density meter, ASTM International, West Conshohocken, Pennsylvania, USA, 2018.

54 J. Chao and F. D. Rossini, Heats of combustion, formation, and isomerization of nineteen alkanols, J. Chem. Eng. Data, 1965, 10, 374-379, DOI: 10.1021/je60027a022.

55 J. Yanowitz, M. A. Ratcliff, R. L. McCormick, J. D. Taylor and M. Murphy, Compendium of experimental cetane numbers, National Renewable Energy Laboratory, NRELTP-540061693, 2017, https://www.nrel.gov/docs/fy17osti/67585.pdf.

56 S. Kim, K. N. Chung and S. Yang, Direct synthesis of ethers via zinc chloride mediated etherification of alcohols in dichloroethane, J. Org. Chem., 1987, 52, 3917-3919, DOI: 10.1021/jo00226a036.

57 X. F. Wu and H. Neumann, Zinc-catalyzed organic synthesis: C-C, C-N, C-O bond formation reactions, Adv. Synth. Catal., 2012, 354, 3141-3160, DOI: 10.1002/adsc.201200547.

58 T. Aulich, Fungibility 101, http://biomassmagazine.com/ articles/2542/fungibility-101, accessed 23 November 2020.

59 B. Bunting, M. Bunce, T. Barone and J. Storey, Fungible and compatible biofuels: literature search, summary, and recommendations, Oak Ridge National Laboratory, 2010, ORNL/TM-2010/120.

60 British Standards Institute, Fuel oils for non-marine use Part 2: Specification for fuel oil for agricultural and industrial engines and burners, BS2869, 2017. 